\title{
SÔBRE A MEIOSE DE DYSDERCUS MENDESI BLOETE (1937) - HEMIPTERA, PYRRHOCORIDE
}

\author{
Luiz O. T. Mendes
}

\section{INTRODUÇÃO}

Em 1936, o autor, quando estudava várias espécies do gênero Dysdercus Amyot \& Serville (1843) (1, 2, 3 e 4) iniciou um pequeno trabalho com o fito de observar possíveis diferenças citológicas entre essas espécies. Estaram em observação, em seu laboratório: Dysdercus mendesi Blocte, $D$. ruficollis (L) e $D$. honestus Bloete. Por essas observações preliminares - que foram feitas em estreita colaboração com o sr. A. J. Teixeira Mendes, Chefe da Secção de Citologia do Instituto Agronômico - verificou-se que havia diferença específica no número de cromossômios.

Se bem que o material se mostrasse bastante interessante para um estudo mais completo, a investigação foi interrompida.

Em 1947, o autor forneceu material vivo das 3 espécies citadas ao Prof. Salvador de Toledo Piza Jr., da Escola Superior de Agricultura "Luiz de Queiroz", que, estudando a meiose nos machos, publicou um trabalho a respeito (5). Os resultados apresentados por êsse autor, relativos à meiose no macho de $D$. mendesi Bloete, em parte concordaram com o que havíamos anteriormente observado; entretanto, permaneceram certas dúvidas. Assim, resolvemos fazer uma pequena revisão, com o fito de esclarecê-las, se possível. Como consequência, verificamos logo que o comportamento dos sexo-cromossômios de Dysdercus mendesi Bloete é bem diverso daquele observado por Piza (5) $(*)$. Fste trabalho dá os resultados obtidos nessa investigação.

\section{MATERIAL E METODOS}

Para o estudo da meiose nessa espécie de inseto, reiniciamos uma pequena criação, em laboratório. A princípio, fazíamos observações ùnicamente em testículos do adulto, mas, para a elucidação de algumas dúvidas, tivemos que estudar também testículos de ninfas. Os dados aqui apresentados foram obtidos de análises de grande número de lâminas, preparadas com orceína-acética; dessa maneira, nada estudamos com referência ao comportamento do nucléolo. As figuras e fotografias apresentadas foram obtidas de muitas lâminas, correspondendo consequentemente a vários

(*) Em trabalho publicado nesta mesm: revist:t. Piaa manifesta seu atual ponto de vista sobre o assunto. 
indivíduos. As fotografias foram tiradas com uma câmara Makam $1 \mathrm{X}$, em microscópio Leitz, objetiva de imersão em óleo $100 \mathrm{X}$, ocular $10 \mathrm{X}$. Os desenhos e fotografias, obtidos de células esmagadas entre lâmina e lamínula, apresentam-se, porisso, com os elementos cromáticos quase todos aproximadamente num único plano; êsie fato, entretanto, não altera as conclusões a que chegamos, uma vez que sempre fizemos um estudo analítieo e interpretatio das figuras obtidas, antes de seu final esmagamento ua lâmina.

O testículo compõc-se de $T$ folículos, a quando se consegue retirar um dêsses tubos, de dentro do tecido escrotal, a observação se torna muito mais simples. Do 3.० instur em diante há uma forte pigmentação vermelha no escrôto, que dificulta muito a observação em esfregaços, tornando quase impossível o estudo das divisões espermatogoniais. Não observamos células en redução nos testículos de ninfas no 2.0 instar; apenas as primeiras fases do ciclo meiótico puderam ser observadas em testículos de ninfas no 3." instar ; do 4." instar em diante pudemos observar tôdas as fases, desde os espermatogônios até a telófase da 2." divisão, e seus consequentes espermatídeos; no $4 .^{\circ}$ instar não encontramos espermatozóides formados. No 5. instar já se completa o ciclo meiótico, de modo a se poder observar, também, os espermatozóides. Portanto, quando um adulto emerge, já está soxualmente maduro.

\section{MEIOSL}

Num folículo testicular, colorido con orceína-acética, encontramos pelo menos três zonas bem distintas, a contar aproximadamente da extremidade apical : a) uma primeira zona, constituída por um número relativamente pequeno de células (zona germinativa) cujos núcleos se apresentam quase sempre fraca e uniformemente coloridos, com aparência granulosa ou reticulada ; b) uma segunda zona (zona de multiplicação) onde os núcleos celulares se apresentam bastante coloridos, nas várias fases da multiplicação dos espermatogônios ; c) uma terceira zona (zona de crescimento) onde os núcleos se apresentam de vários tamanhos, e onde se observam sempre os sexo-cromossômios bem coloridos e individualizados, em contraste com a cromatina restante, em outras fases de seu ciclo. Já nessa zona, mas principalmente depois, encontram-se bem delimitados os cistos, contendo número variável de células, cada conjunto numa mesma fase, isto é, observa-se sincronimmo na crolução celular de cada cisto.

Espermatogônios - (O núcleo em repouso (fig. 1) apresenta-se com asperto granuloso, ou um tanto reticulado, rom a cromatina uniformemente distribuída. Na prófase aparecem os filamentos em enovelamento difícil de ser estudado, formando-se depois a placa metafásica (foto 1), constituída por 16 cromossômios (figs. 2 e 3). Na metáfase observa-se fàcilmente a presença de 4 pares de autossômios bem grandes, bastonetes grossos e um pouco recurvados, 1 par de autossômios menores, bastonetes grossos a curtos; dos outros 3 pares, pequenos, dois são autossomais e um é constituído pelos sexo-cromossômios, difícejs, entretanto, de serem determinados quais sejam. 
Não logramos observar anáfases espermatogoniais, de modo que não podemos aqui discutir de que maneira se dá a divisão dos cromossômios. O que notamos é que, depois da última divisão espermatogonial, os 2 sexocromossômios ficam isolados, dentro de uma sorte de bolsa ou vesícula, enquanto a cromatina dos autossômios se difunde no nucleoplasma ; assim, o núcleo toma um asperto granuloso uniforme, no seio do qual se encontram duas pequenas bolsas, isoladas uma da outra, contendo cada uma um dos sexo-cromossônios. Está formado o espermatócito I.

Espermatócito 1 - Antes do período de crescimento do núcleo, os sexo-cromossômios aumentan um pouco de tamanho (fig. 4) e, ao mesmo tempo, a cromatina dos autossômios principia a se condensar, dando ao núcleo uma coloração mais escura; com o desenvolver do ciclo, mais se adensa a cromatina autossômica, alterando o aspecto nuclear - antes granuloso - como que formando pequenos glomérulos, enquanto os sexocromossômios, ainda contidos dentro de suas respectivas bolsas, continuam a aumentar de tamanho, tornando-se mais alongados (fig. 5). Em certo momento, quando atingem seu máximo de desenvolvimento, as bolsas continentes se desfazem e os sexo-cromossômios, já com a forma de dois longos bastonetes, sempre bem coloridos, movimentam-se dentro do nucleoplasma ; procurando aproximar-se um do outro (fig. 6), até colocarem-se lado a lado, tocam-se e, com o aparecimento de uma fissura, o conjunto toma um aspecto tetradiforme (fig. 7). Nesse estado dá-se uma certa contração no tamanho dos sexo-cromossômios, de modo que a tétrade fica finalmente com cêrca de $50 \%$ de seu volume anterior à contração. Começam os autossômios a se tornar agora visíveis, sob a forma de longos filamentos, pareados, ao longo dos quais se notam grânulos. Nesse estado, em que o núcleo é relativamente pequeno, é difícil, se não impossível, contar-se o número de filamentos existentes. Os sexo-cromossômios, que se encontravam unidos, ou assim continuam ou já se separam, formando dois cromossômios independentes, bastante coloridos, e à distância variável um do outro (foto 2). $O$ núcleo entra em crescimento e os sexo-cromossômios continuam unidos (fig. 8) naquelas células onde seu ciclo se vem desenvolvendo mais atrazadamente, ou separados (fig. 9), nas células em que seu ciclo está mias adiantado. Os autossômios entram em pachytene (fig. 10 e foto 3), o enovelamento primitivo se vai abrindo, de sorte a poder-se, em certos casos, contar a presença de 7 longos pares de filamentos. Depois da fase pachytene, o núcleo continua a crescer, e entra no estado difuso, isto é, os autossômios vão aos poucos se difundindo e o núcleo toma um aspecto granuloso, não uniforme, pois se notam pequenos adensamentos de cromatina esparsos no nucleoplasma (fig. 11). Nesta fase os sexo-cromossômios podem ainda se encontrar unidos (foto 4), com o referido aspecto tetradiforme, ou já separados. De qualquer maneira, mesmo nas células onde os sexo-cromossômios estão com sua evolução mais atrazada, separam-se êles durante o estado difuso do núcleo, e observa-se então que êles possuem uma nítida cintura mediana, que os separa em duas partes idênticas (fig. 11). O núcleo ainda cresce mais um pouco e os sexo-cromossômios continuam separados, bem coloridos e com o mesmo tamanho anteriormente observado ; a croma- 
tina autossômica vai novamente se adensando em certos pontos do nucleoplasma (fig. 12 e foto 5 ), formando 7 agrupamentos distintos que, aos pouros, se vão individualizando nas futuras tétrades autossomais. A cromatina toma estão um aspecto aparentemente filamentoso (parece tratar-sc da fase diplotene), sendo fàcilmente contados os 7 pares de autossômios ; os sexo-cromossômios continuam afastados um do outro, e heteropienóticos: (fig. 13). A medida que os autossômios se vão condensando, para a formação das tétrades autossômicas (fig. 14), os sexo-cromossômios sè vão tornando difusos e menos coloridos, e alongando-se até tomarem o aspereto de pares de filamentos, ficando, então, com a aparência de cromossômios em pachy tene. Nesso estádio do núcleo, os autossômios se apresentam mais coloridos que os sexo-cromossômios, e é possíncl notar-se que êstes últimos são constituídos por dois únicos filamentos, dispostos longitudinalmente (fig. 14 e foto 6). Na diakinesis nota-ne, com frequência c facilidade, a formação de cruzes (fig. 14 e foto 7 ) ou anéis (foto 7 ). Nessa fase da evolução celular, os sexo-cromossômios apresentam-se menos conde'nsados que os autossômios, e, portanto, menos coloridos que êstes (foto $\tau$ ). Num núcleo em diakinesis, os autossômios encontram-se na sua periferia, e os sexo-cromossômios, afastados um do outro, em qualquer posição intranuclear. Aproximando-se a metáfase, as tétrades autossômicas se vão condensando cada vez mais, dispondo-se em círeulo, encuanto os sexocromossômios tomam o aspecto de cromossômios em diakinesis (contração e alteração em sua conformação geral) e dirigem-se para o centro dêsse círculo aproximando-se cada vez mais um do outro (fig. 15 e 16). Quando em metáfase, os autossômios acham-sc dispostos na linha do equador, em seu máximo de contração, e os sexo-cromossômios, bastante próximos um do outro, igualmente alinhados, porém não no mesmo estado de contração e adensamento notado nos autossômios (fig. 17). Nessa fase os sexo-cromossômios apresentam-se bem pequenos, alongados, e com uma bem visível cintura mediana e, como já foi dito, um pouco menos coloridos que as tétrades autossômicas (fotos 9 e 10). Destas últimas, em número de 7 , quatro são bastante grandes, uma é um pouco menor e outras duas menores ainda ; em certos casos nota-se que, destas duas últimas, uma é ainda menor que a outra, porém sempre maior que os sexo-cromossômios. Na metáfase I, portanto, são encontrados 7 bivalentes e 2 univalentes, dispostos no equador.

$\mathrm{Na}$ anáfase I (fig. 18), as tétrades autossomais, bastante curtas, entram em separação pela constrição francamente visível nos estádios anteriores e, na maioria das vêzes, suas metades ficam ligadas por meio de dois conectivos interzonais bastante nítidos (figs. 18 a 20 e foto 11) ; em certos casos não pudemos observar senão um único conectivo interzonal en algumas tétrades autossômicas em anáfase (fig. 19). Os sexo-cromossômios se separam e suas metades ficam ligadas sempre por um único conectivo interzonal. No decorrer da anáfase, ao se dirigirem para os pólos, os sexo-cromossômios se vão aproximando um do outro, de modo que já em anáfases adiantadas estão em contacto (fig. 20 e fotos 12 a 14), e na telófase se unem intimamente, formando um único elemento cromático com uma fenda no sentido da ligação (fig. 21 e foto 15). A união dos dois sexo-cromossômios se dá no seu primitivo sentido longitudinal, de modo que é de se supor que os 
dois primitivos pontos de inserção (por onde cada uma de suas metades foi levada para o pélo) tenham se disposto lado a lado.

Dessa maneira, observa-se fàcilmente, em vista polar, no espermatócito II, oito elementos (romáticos, sendo dois sexo-cromossômios soldados: num único clemento, e sete autossômios (fig. 21).

Espermatócito II -- () núcleo entra em incerkinesis (fig. 22), os autossômios se colorem fracamente, porém os sexo-cromossômios continuam bem densos (foto 16), bastante coloridos, e exatamente com a mesma forma e tamanho adquiridos na telófase I. Adensa-se novamente a cromatina dos autossômios c êstes se dispôem em círculo, no equador, orientando-se para a segunda divisão. () ('onjunto sexo-cromossômico muitas vêzes tambén se coloca no equador (fig. 23), com a mesma orientação dos autossômios, mas temos visto muitos casos em que êle não se acha aí situado, mas sim afastado do equador, a distânciass variáveis de um dos pélos, ou nas suas proximidades. Os autossômios começam a se separar, notando-se perfeitamente um afilamento produzido em sua extremidade dirigida para o ṕlo. enquanto o par de sexo-cromossômios continua com sua forma imutável, sem se separar, porém se adiantando no movimento em direção ao p’lo que lhe fica mais próximo (fig. 24 e foto 17 ). A medida que a anáfase evolui, o par de sexo-cromossômios, sempre inteiro e imutável em sua forma, mais se aproxima de um dos pólos (fig. 25 e fotos 18 e 19). Nota-se fàcilmente que os autossiomios são encaminhados para os pślos por intermédio de uma única fibrila, assim como suas metades ficam ligadas por um único conectivo interzonal. Em casso algum pudemos observar os autossômios se adiantarem para os pólos, deixando atrás o par de sexo-cromossômios; todos os casos observados, portanto, são de precessão. Terminada a divisão, encuanto um pćlo recebe 7 autossômios, o outro recebe 8 cromossômios: sendo 7 autossômios e um par de sexo-cromossômios unidos. Fm certos casos, pudemos observar uma leve fissura longitudinal nos autossômios, em anáfases adiantadas, indicando já um início de divisão dos cromatídeos. Na telófase II, portanto, contam-se núcleos com 7 e núcleos com 9 cromossômios (fig. 26).

Espermatídeos - Formados os espermatídeos, os autossômios começam a se tornar difusos, de modo a se poder observar núclcos com 7 adensamentos de cromatina, e núcleos com êsses mesmos 7 adensamentos de cromatina e um par de sexo-cromossômios em estreita união (diade), bem visivel (fig. 27 e foto 20). A cromatina dos autossômios cada vez mais se difunde. de modo que, afinal, nos núcleos que receberam ùnicamente os 7 autossômios se nota seu aspecto reticulado, enquanto aquêles que receberam a mais a diade sexo-cromossômica apresentam o nucleoplasma com aquêle mesmo aspecto reticulado, porém com um bem visível e colorido elemento cromático. - o par de sexo-cromossômios unidos (foto 21).

Dessa maneira formam-se espermatozóides com 7 cromossômios (autossômios) e espermatozóides com 9 cromossômios ( 7 autossômios e ự par. de sexo-cromossômios uniclos). 


\section{DISCUSSÃO}

O estudo da meiose em Dysdercus mendesi Bloete apresentou aspectos bastante interessantes, alguns bem complicados em sua interpretação. Porisso deixamos para um próximo trabalho, já em preparo, uma discussão. detalhada do ciclo meiótico do sexo-cromossômio, bem como de sua morimentação no interior do nucleoplasma. Nessa ocasião serão também discutidos vários fatos relativos ao modo de pareamento e divisão dos cromos-sômios dêsse inseto.

Em resumo, apresentamos as seguintes

\section{CONCIUSÕES}

1 - Os espermatogônios de Dysdercus mendesi Bloete têm 16 cromossômios, dos quais sete pares de autossômios e dois sexo-cromossômios.

2 - Depois da última divisão espermatogonial, enquanto a cromatina dos autossômios se difunde, dando um aspecto granuloso uniforme ao nucleoplasma, cada sexo-cromossômio fica protegido dentro de uma bolsa, mantendo-se bem colorido.

3 - Enquanto a cromatina dos autossômios se vai adensando, para finalmente formar os longos filamentos que são vistos pareados longitudinalmente, o par de sexo-cromossômios sofre a seguinte evolução:

a) ainda dentro das bolsas, aumentam de tamanho, tomando a forthia de longos bastonetes :

b) libertam-se da bolsa protetora, aproximam-se um do outro, e dispriemse longitudinalmente, formando um par;

c) tocam-se, fissuram-se e formam um elemento cromático tetradifurmc. que se contrai e diminui de volume, sempre, porém, bem colorido.

4 - Durante todo o período de crescimento do espermatócito. é observada a hetero-pienose dos sexo-cromossômios.

5 - A separação da tétrade sexo-cromossômica, em dois cromossômios, dá-se tanto no início do período de crescimento do núcleo (quando os autossômios se apresentam como longos pares de filamentos), como em qualquer outro período dessa fase. Tal separação se dá, o mais tardar, no estado difuso do núcleo.

6 - Quando os autossômios estão em diakinesis, o par de sexocromossômios toma o aspecto de cromossômios em pachytene.

7 - Na metáfase I as tétrades autossômicas apresentam-se com a cromatina mais condensada que os sexo-cromossômios. Estes dirigem-separa o centro do círculo formado pelos autossômios, aproximando-se bastante um do outro, sem se tocarem.

8 - Na anáfase I a maioria das tétrades autossômicas mostra dois conectivos interzonais, enquanto só é observada uma dessas fibrilas ligando os elementos em separação, dos sexo-cromossômios. $\mathrm{Na}$ movimentação para os pólos, os sexo-cromossômios se vão aproximando um do outro. 
9 - Na telófase I os sexo-eromossômios se tocam em seu sentido longitudinal, e se unem, formando um único elemento cromático.

10 - Na metáfase II os autossômios se colocam no equador. O par de sexo-cromossômios (unidos) tanto é encontrado no equador como fôra dêle.

11 - Na anáfase II os autossômios se separam normalmente, cada pj́lo recebendo um dos cromatídeos. Observa-se a existência de um fraco conectivo interzonal. $O$ par de sexo-cromossômios não se separa, continua unido, e dirige-se intciro para um dos pólos, sempre em precessão.

12 - Formam-se duas sortes de espermatídeos; a) com 7 autossômios ; b) com 7 autossômios e um par de sexo-cromossômios constitú́do por dois cromossômios unidos.

13 - Nas primeiras fases da espermatogênese, os núcleos que receberam 7 autossômios apresentam aspecto reticulado ; enquanto nos núcleos que receberam a diade sexo-cromossômica, esta se mantém imutável em sua forma, com uma fenda no sentido da união dos dois cromossômios, bem visível.

14 - O macho de Dysdercus mendesi Bloete é de constituição cromossômica $7 \mathrm{AA}+\mathrm{XX}$.

\section{NOTA}

A fêmea de Dysdercus mendesi Bloete tem $210=18$ cromossômics, isto é, $2 \mathrm{n}=14 \mathrm{~A}+4 \mathrm{X}$.

\section{AGRADECIMENTOS}

$\mathrm{O}$ autor deixa aqui consignados seus melhores agradecimentos ao sr. A. J. Teixeira Mendes, Chefe da Secção de Citologia do Instituto Agronômico, pelos auxílios prestados durante esta investigação, bem como pelas sugestões apresentadas.

\section{SUMMARY}

1 - The spermatogonia of Dysdereus mendesi Blocte have 16 chromosome: 7 pairs of atutosomes and 2 sex-chromosomes.

2 -- After the last spermatogonial division. the chromatin of the autosomes diffuses and the nucleoplasm assumes an uniform granular aspert : each sex-chromosome is involved by a vesicle and stands well colored.

3 - While the chromatin of the autosomes starts to condense again, to for $m$ the long threads (that finnally are seen in a paired condition) the cycle of the sex-rehromosomes is as follows:

a) yet rontained in the vesirles, they grow in size and berome long rods :

b) the vesicles disappear, the sex-chromosomes move inside the nucleoplasm and come to be disposed longitudinally, close together.

c) they touch ewch other, become fissured, and a tetradlike chromatic element is formed, which contracts itself. remaining always well colored.

4 - The hetero-pyenosis of the sex-chromosomes is observed through the whole grow phase of the spermatoryte I.

5 - The separation of the sex-chromosome tetrad. originating two independent sex-chromosomes, is observed in the early grow phane of the spermatocyte as well as during any other period of this phase. The latest separation is observed during the diffuse stage of the nucleus. 
6 - When the autosomes are in diakinesis, the sex-chromosomes assume the aspect of chromosomes in pachytene.

7 - In metaphase I the autosomic tetrads are in a more condensed and colored condition than the sex-chromosomes. The sex-chromosomes move to the renter of the autosome-forming circle, but there is no contact between them.

8 - In anaphase $I$ it is obscrved 2 interzonal connections between each autosomic dyad ; some exceptions are observed. Only one interzonal connestion is observed between the separating sex-chromosomes. Moving to the poles the sex-chromosomes also approximate one to the other.

9 - In telophase I the sex-chromosome touch each other, and fuse side-by-side. forming only one chromatic element. The line of fusion is well visible through the subsequent stages of meiosis.

10 -- In metaphase II the autosomes are disposed at the equator. The sex-chromosome dyad is also disposed at the equator, as well as at any other position.

11 - In anaphase II the separation of the autosomes is normal, and it is seen only one interzonal connection between its halves. The sex-chromosome dyad do not separate and moves to one pole. always in precession.

12 - There are two rlasses of spermatids : a) with 7 autosomes; b) with 7 autosomes plus the sex-chromosome dyad.

13 -- During the first phases of the spermatogeneses the 7-autosome containing nucleus presents a reticulated aspect ; the sex-chromosome-dyad containing nucleus shows this chromatic element well colered inside the reticulated nucleoplasm.

14 - The male of Dysdercus mendesi Bloete has $7 \mathrm{AA}+\mathrm{XX}$ chromosomes.

NOTE - A discussion on the movements of the sex-chromosome and its cycle. as well as on some aspects of the pairing of the autosomes, is being prepared. It will be published in the vear future. The female of Dysdercus mendesi Bloete has $2 \mathrm{n}=14 \mathrm{~A}+4 \mathrm{X}$.

\section{LITERATLIRA CITADA}

1. Mendes, Luiz O. T. Os "Manchadores do Algodion" (Dysdercus spp.). Inst. Agr. Bol. Tern. 23 (II) : 1-23, 2 ext., Campinas, 1936.

2. Mendes, Luiz O. T. Sôbre algumas espécies de Dysdercus do Brasil e do Perú, Rev. Fint. VII (1-2) : 204-205, Rio de Janeiro, 1938.

3. Nendes, Luiz O. 'T. Genetic's of Distercus. I. Behaviour of a melanic form (mm) of Dysdercus mendesi Bloete. Jour. Hered. XXIX (10): 387-391, N. York. 1938.

4. Mendes, Luiz O. T. (Genetics of J) $/$ selerws. II. Belaviour of a yellow striped form of Dysdercus mendesi Blocte. Journ. Hered. XXX (11): 498. X. York, 1939.

5. Piza, S. de Toledo, Jr., (romonsomios de Dysedercus (Hemiptera-Phyrrhocoridąe). Ann. Isc. Sup. Agr. "Iaiz do (Queiroz". $+(6 ;)): 209-216.14$ fig., Piracioaba. 1947.

\section{EXPLICACTO DAS FIG RAS DAS RSTAMPAS 1 a 3}

1. Espermatogônio. Xúcleo em repousos. $2.500 \mathrm{X}$.

2. Metáfase espermatogonial ( $2 \mathrm{n}=16$ ('romossomios). $2.500 \mathrm{X}$.

3. Metáfase espermatogonial $(2 n=16$ ('romossomios) $2.500 \mathrm{X}$.

4. Espermatócito I. $2.500 \mathrm{X}$.

5. Hspermatócito I. $2.500 \mathrm{X}$.

6. Espermatócito I. $2.500 \mathrm{X}$.

7. Hspermatócito I. $2.500 \mathrm{X}$.

8. Espermatócito 1 em crescimento, $\mathrm{O}$ pal de sexo-cromossômios está unido. $2.500 \mathrm{X}$. 
9. Espermatócito I em rrexcimento. O par de sexo-cromossônios se separou. $2.500 \mathrm{X}$.

10. Pachytene. Os sexo-(comossômios estão unidos, formando uma tétrade. $2.500 \mathrm{X}$.

11. Estado difuso do núcleo. 2.500 X.

12. Aspecto de um núcleo depois da fase difusa. 2.500 X.

13. Diplotene. $2.500 \mathrm{x}$.

14. Diakinesis. Os rexorromossômios estão eom aspectu de cromossômios em pachytenc. $2.500 \mathrm{X}$.

15. Metáfase I. 2.i00 X.

16. Metáfase I. Vista polar. 2.500 X.

17. Metáfase I. Vista equatorial. $2.500 \mathrm{X}$.

18. Anáfase I. $2.500 \mathrm{X}$.

19. Anáfase I. 2.500 $\mathrm{I}$.

20. Anúfase I. 2.500 X.

21. Telófase I. Os sexo-rromosonnios se uniram. 2.500 X.

22. Interkinesis. 2.500 X.

23. Metáfase II. $2.500 \mathrm{X}$.

24. Anáfase II. $2.500 \mathrm{X}$.

25. Anáfase II. $2.500 \mathrm{X}$.

26. Telofase II. $2 . \overline{500 ~} \mathrm{X}$.

27. Espermatídeos $(n=9$ e $n=7) .2 .500 \mathrm{X}$.

\section{EXPLICAC̣̃̃o DAS FOTOS DAS ESTAMPAS 4 e 5}

1. Metáfase espermatogonial ( $2 \mathrm{n}=16$ cromossômios). $1.000 \mathrm{X}$.

2. Espermatócito I. Em alguns núcleos o par de sexo-cromossômios está unido, noutros está separado. $1.000 \mathrm{X}$.

3. Pachytene. Os sexo-cromossômios estão separados. $1.000 \mathrm{X}$.

4. Estado difuso do núcleo. Os sexo-cromossômios ainda estão unidos. $1.000 \mathrm{X}$.

5. Aspecto de um núcleo depois da fase difusa. $1.000 \mathrm{X}$.

6. Diakinesis. Os sexo-cromossômios (assinalados por flechas) estaa com o aspecto de cromossômios em pachytene. $1.000 \mathrm{X}$.

7. Diakinesis. Notem-se autossômios formando cruzes e anéis. $1.000 \mathrm{X}$.

8. Diakinesis. Os sexo-romossômios (assinalados por flechas) estaño menos condensados que os autossômios. $1.000 \mathrm{X}$.

9. Metáfase I. $1.000 \mathrm{X}$.

10. Metáfase I. Vista equatorial. $1.000 X$.

11. Anáfase I. $1.000 \mathrm{X}$.

12. Anáfase I. Os sexo-cromossônios entraram em rontarto. $1.000 \mathrm{X}$.

13. Anáfase I. Os sexo-romossômios (assinalados por flechas) entraram en rontacto. $1.000 \mathrm{X}$.

14. Anáfase I. Os sexo-‘romosionmios (assinalados por flechas) entraram em contacto. $1.000 \times$.

15. Telófase I. Os sexomomossomios se uniram. $1.000 \mathrm{X}$.

16. Interkinesis. $1.000 \mathrm{X}$.

17. Anáfase II. $1.000 \mathrm{X}$.

18. Anáfase II. $1.000 \mathrm{X}$.

19. Anáfase II. $1.000 \mathrm{X}$.

20. Hspermatídeos $(n=9$ e $n=7) .1 .000 \mathrm{X}$.

21. Espermatídeos. Im núoleo tem $n=7$ e 0 outso tem $n=9.1 .000 \mathrm{X}$. 

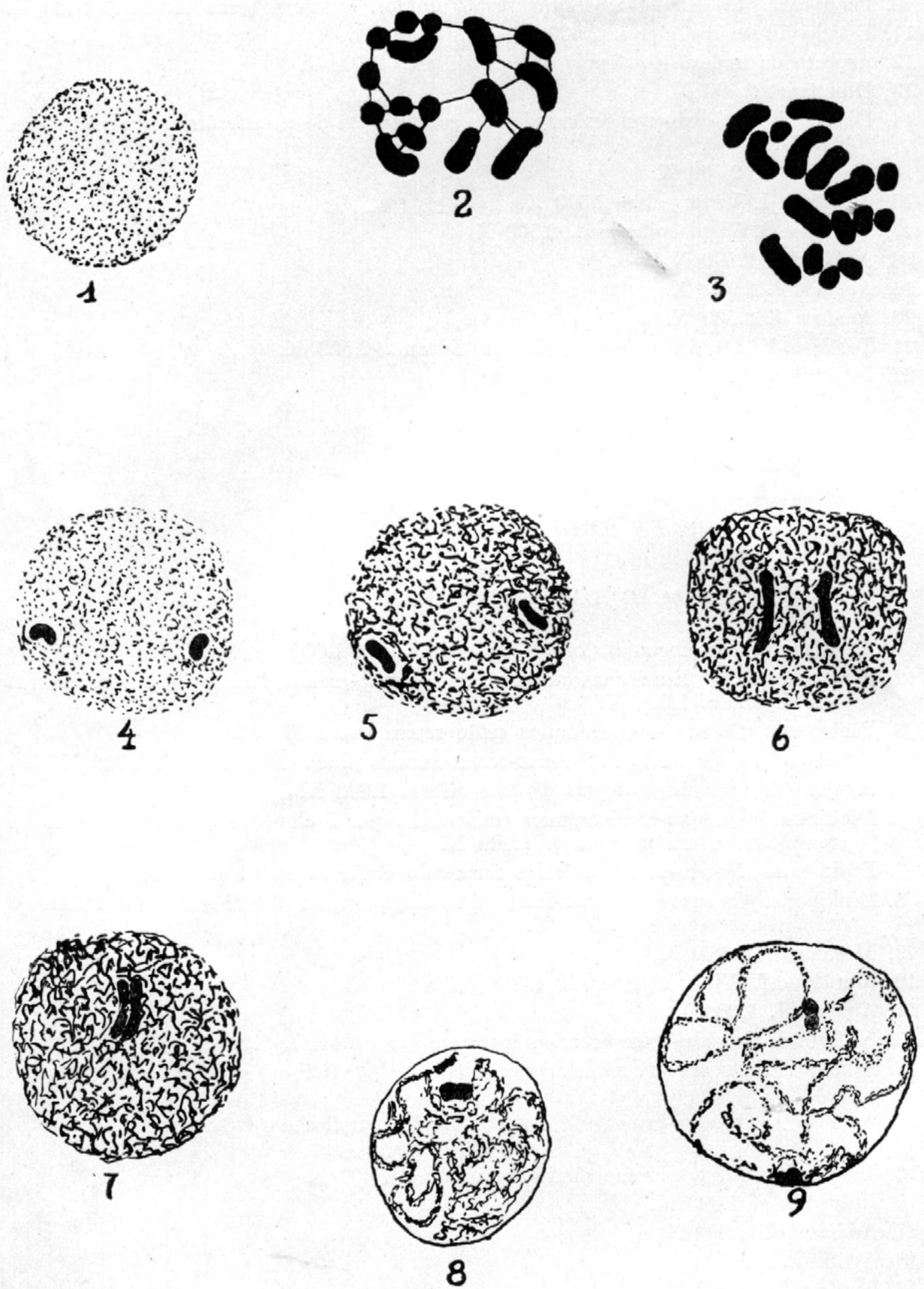
Est. 2
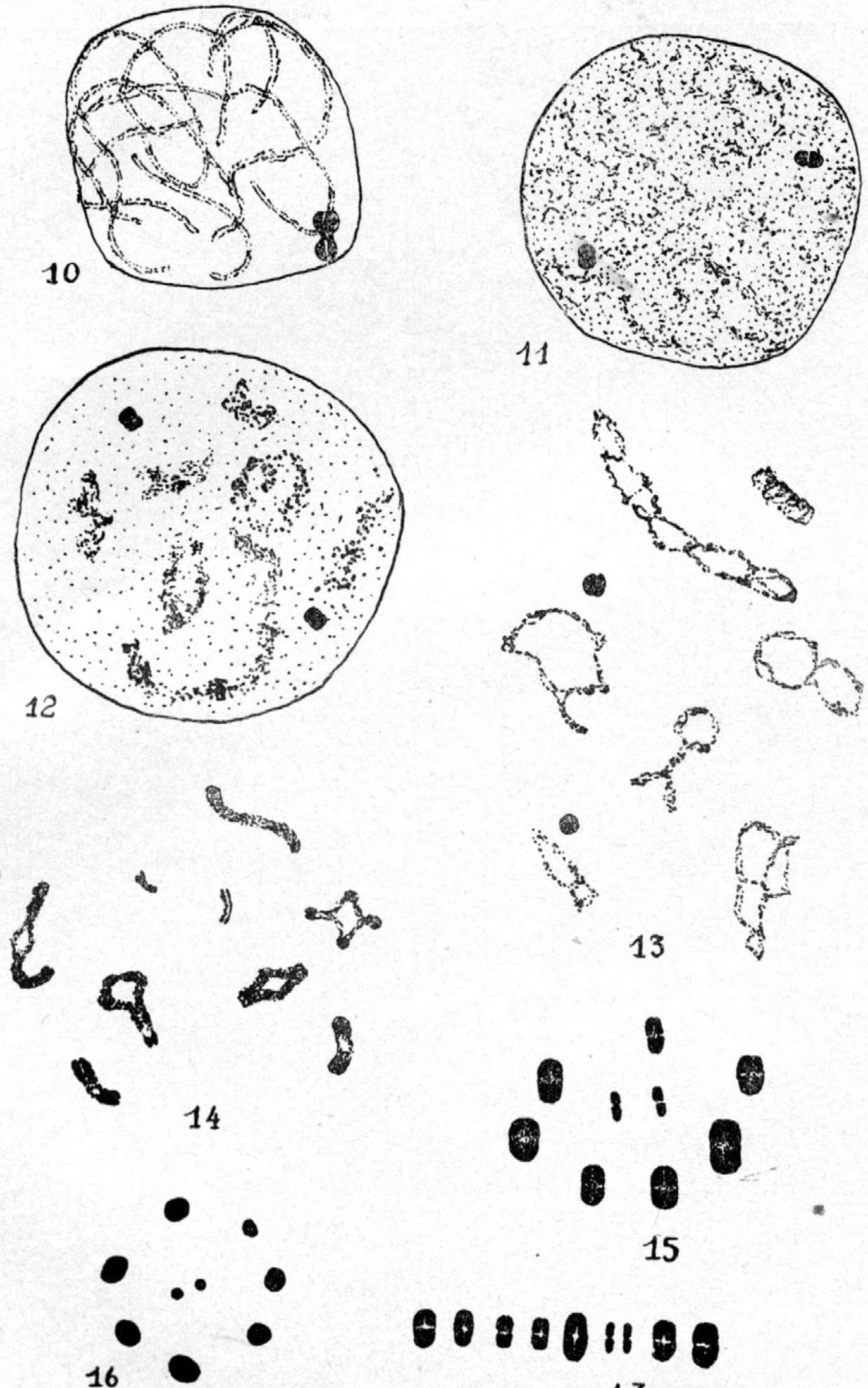

15 
MAIICA

18

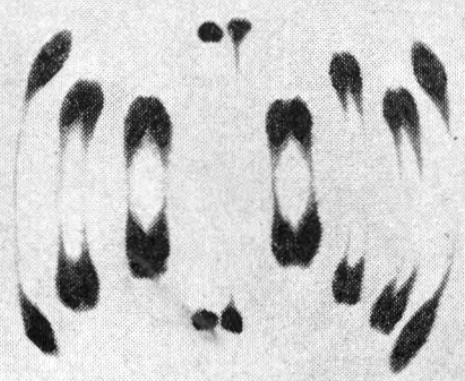

19

"n

:

21

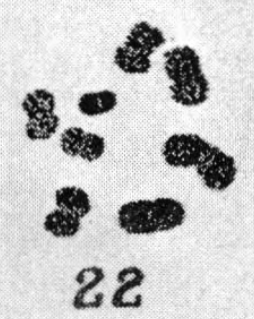

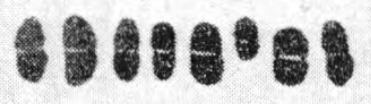

23

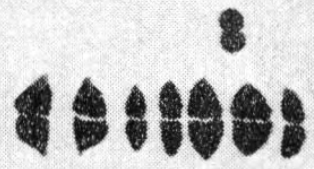

24

coint

\%:

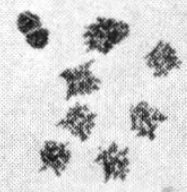

neveso

25

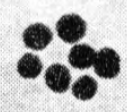

26

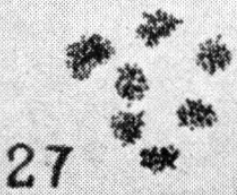


Est. 4
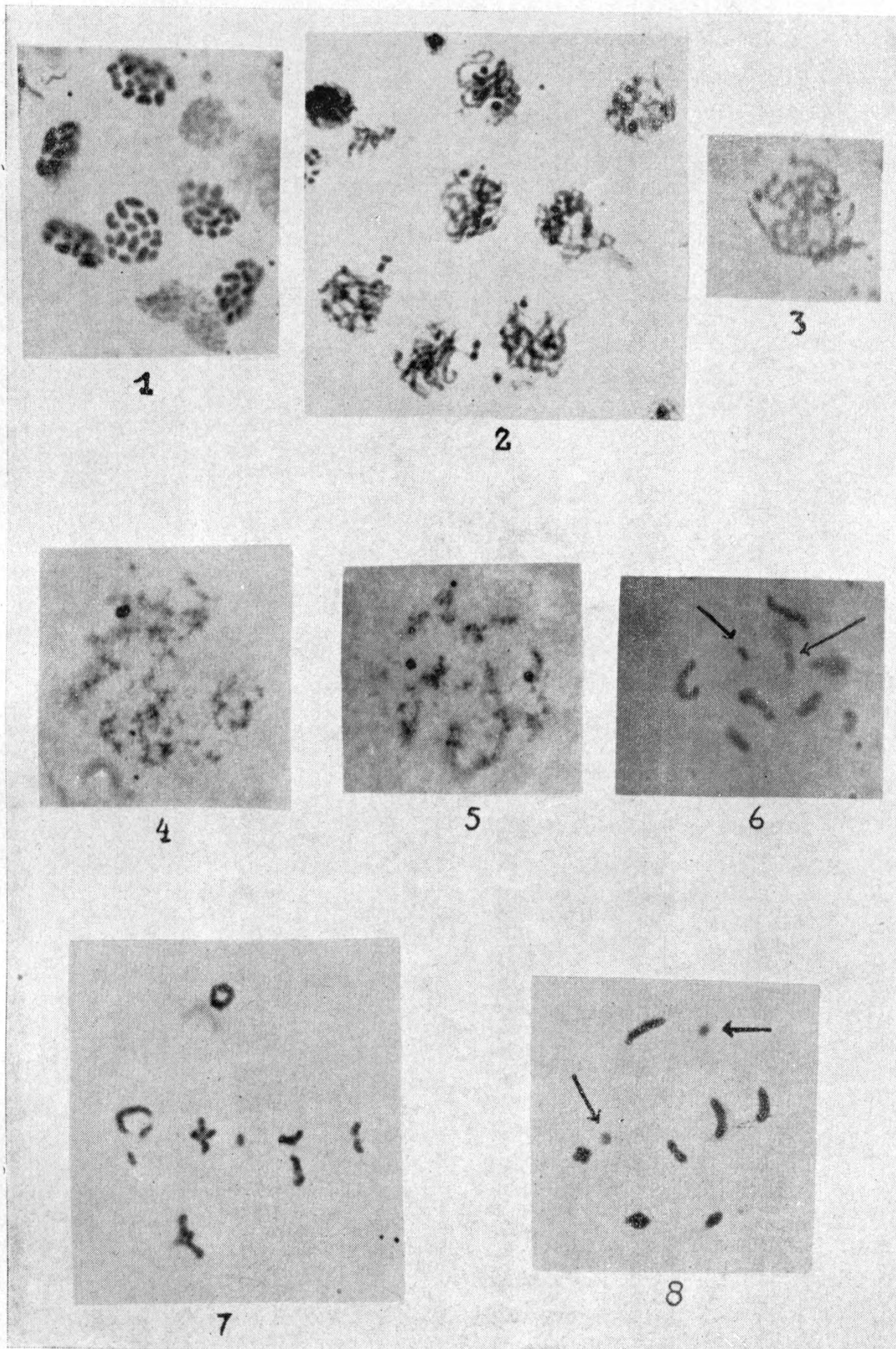
Het. 5
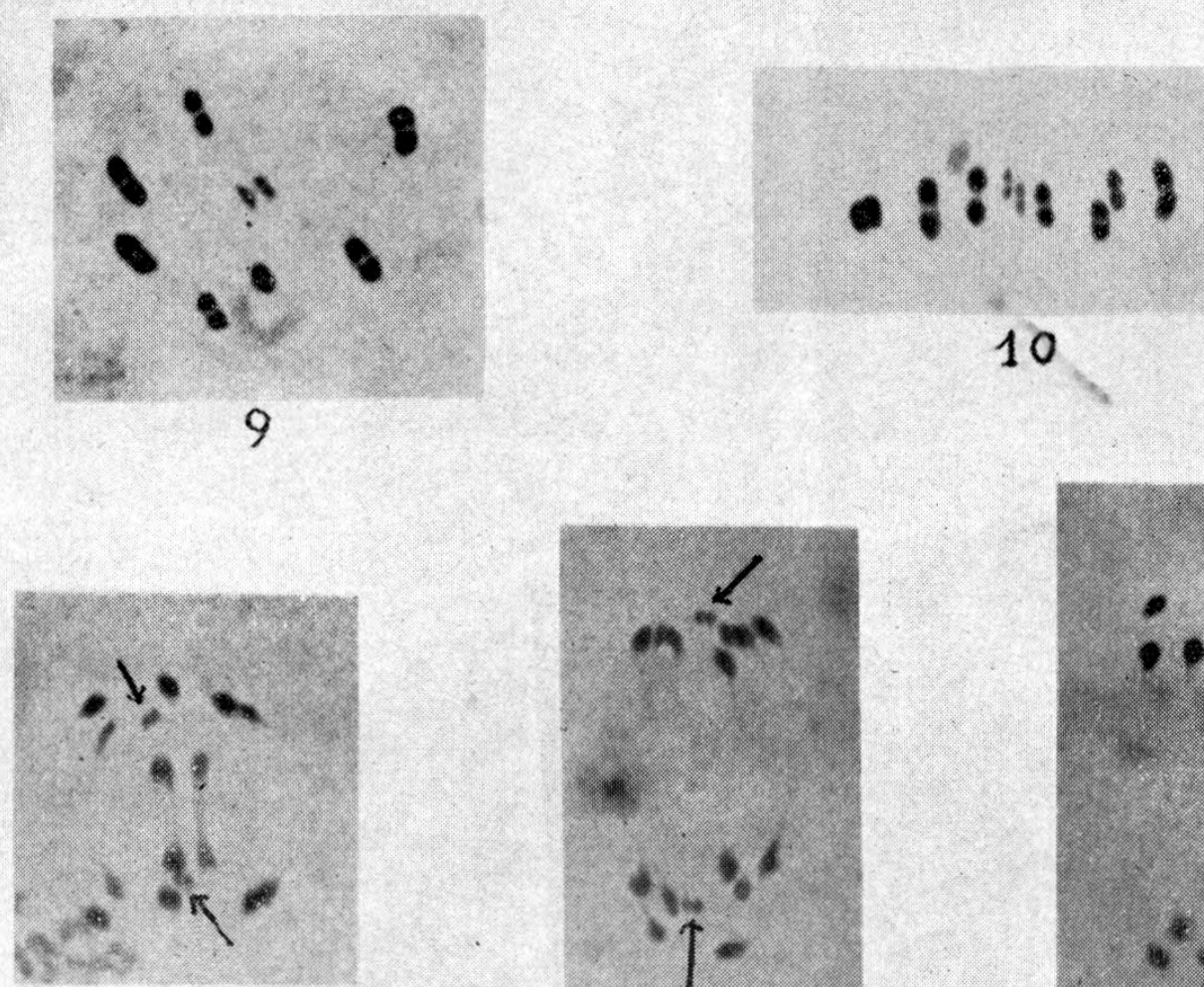

$$
11
$$

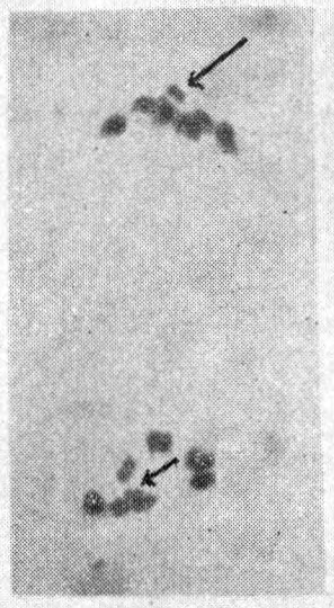

14
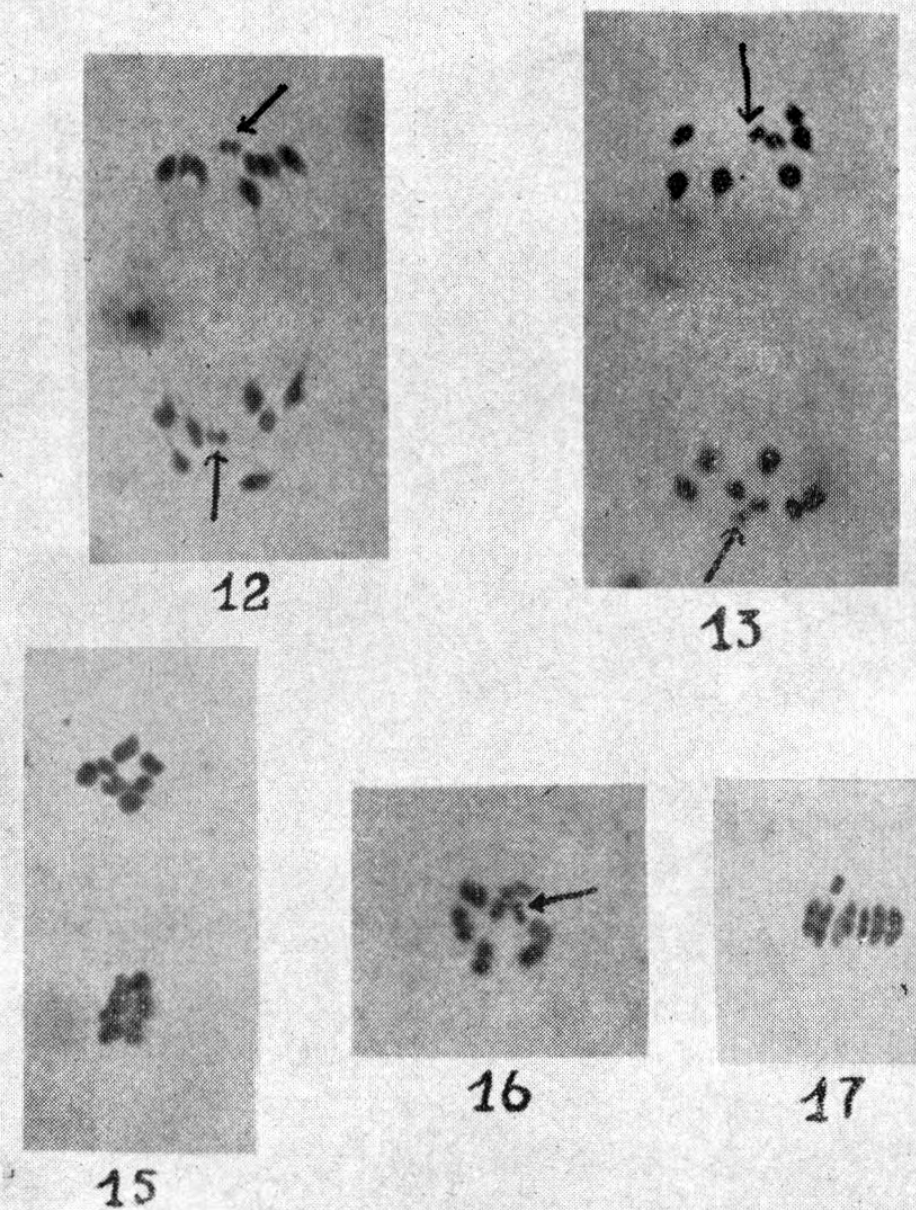
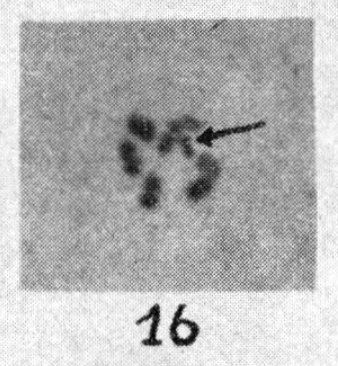

บำ18

17
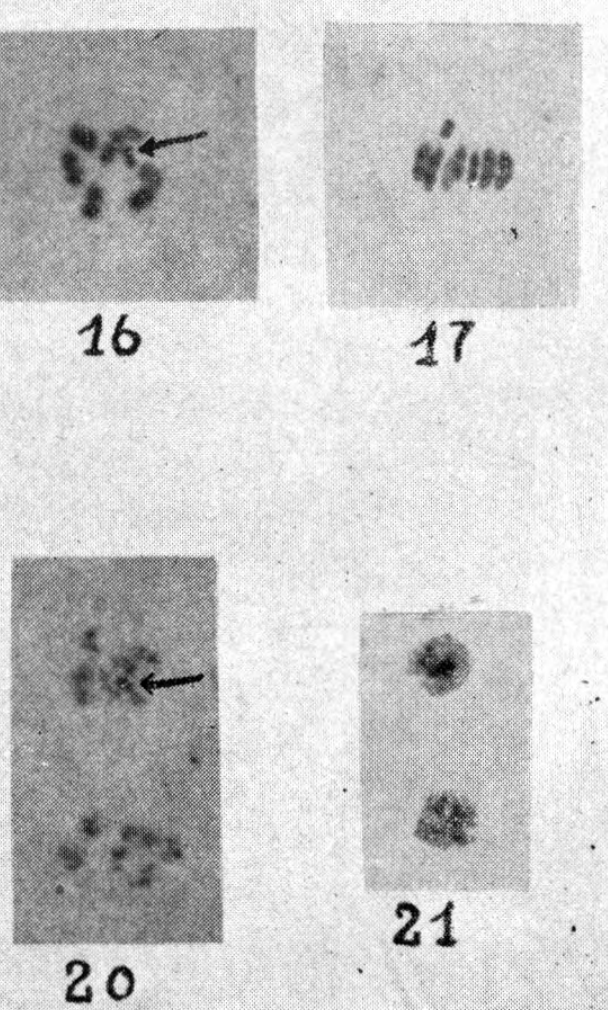

$18 \quad 19$

$18 \quad 19$

toless.

$1+6$ 